This item was submitted to Loughborough's Research Repository by the author.

Items in Figshare are protected by copyright, with all rights reserved, unless otherwise indicated.

\title{
Model for performance based land area and water allocation within irrigation schemes
}

PLEASE CITE THE PUBLISHED VERSION

PUBLISHER

(C) Springer Verlag

LICENCE

CC BY-NC-ND 4.0

REPOSITORY RECORD

Gorantiwar, S.D., and lan K. Smout. 2019. "Model for Performance Based Land Area and Water Allocation Within Irrigation Schemes". figshare. https://hdl.handle.net/2134/3673. 
This item was submitted to Loughborough's Institutional Repository by the author and is made available under the following Creative Commons Licence conditions.

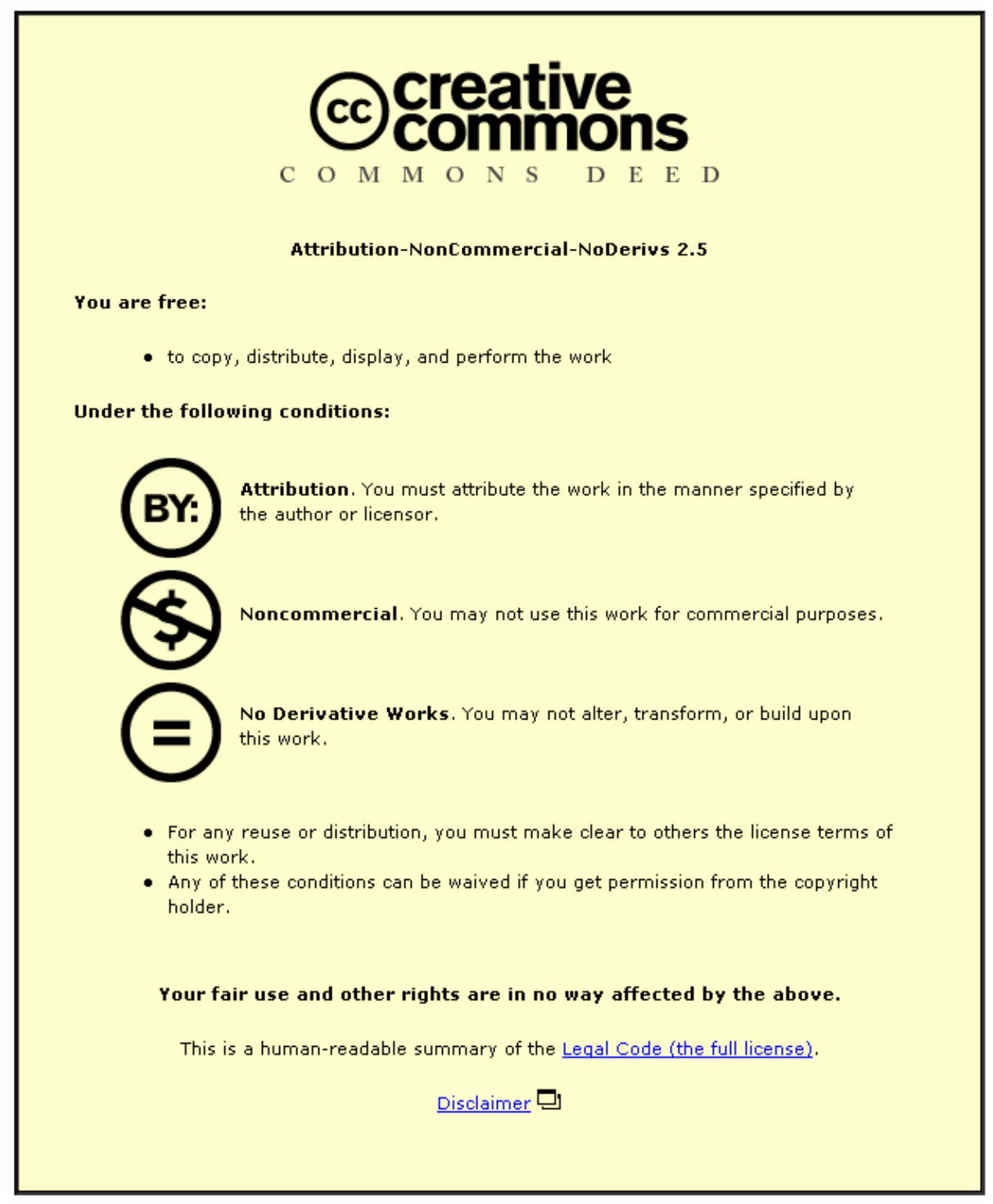

For the full text of this licence, please go to: http://creativecommons.org/licenses/by-nc-nd/2.5/ 


\title{
Model for performance based land area and water allocation within irrigation schemes
}

\author{
S.D.GORANTIWAR ${ }^{1} \&$ I.K.SMOUT ${ }^{2}$
}

${ }^{1}$ Associate Professor, Department of Irrigation and Drainage Engineering, Mahatma Phule Agricultural University, Rahuri, Maharashtra, India and currently Academic Visitor, Water, Engineering and Development Centre, Loughborough University, Leicestershire, LE11 3TU, UK (s.d.gorantiwar@lboro.ac.uk);

${ }^{2}$ Director, Water, Engineering and Development Centre, Loughborough University, Leicestershire, LE11 3TU, UK (email: i.k.smout@lboro.ac.uk)

Corresponding Author: I. K. Smout 
Abstract: This paper focuses on irrigation schemes under rotational water supply in arid and semiarid regions. It presents a methodology for developing plans for optimum allocation of land area and water, considering performance measures such as productivity, equity and adequacy. These irrigation schemes are characterized by limited water supply and heterogeneity in soils, crops, climate and water distribution network etc. The methodology proposed in this paper, therefore, uses a previously developed simulationoptimization model (Area and Water Allocation Model, AWAM) that considers the heterogeneity of the irrigation scheme in the allocation process, and modifies this to take account of equity and adequacy of supply to irrigated areas. The AWAM model has four phases to be executed separately for each set of irrigation interval over the irrigation season: 1. generation of irrigation strategies for each crop-soil-region combination (CSR unit), 2. preparation of irrigation programmes for each irrigation strategy, 3. selection of specified number of irrigation programmes for each CSR unit and 4. optimum allocation of land area and water to different parts of the irrigation scheme (allocation units) for maximizing productivity. In the modified AWAM model, the adequacy is included at Phase-2 (by including only the irrigation programmes for full irrigation of each CSR unit) and equity is included at Phase-4 (by including the constraints for equity). The paper briefly discusses the applicability of the modified AWAM model for a case study of Nazare medium irrigation scheme in Southern India. The results of the case study indicated that the performance measures of productivity, equity and adequacy conflict with each other.

Keywords: water allocation; irrigation; optimization; surface irrigation; performance; productivity; equity; adequacy 


\section{Introduction}

During the past several decades, increasing water demand for irrigation has been met by developing new sources of water. However, the technical, economic and environmental costs associated with the continued development of new sources make this approach undesirable for fully meeting future growth. On the other hand, in many countries the allocation of water for irrigation is viewed as a low priority. As a result, more recently, irrigation has received a reduced share of the total supply due to increased demand from higher valued uses such as industrial, domestic and recreational. For example, in developing countries the share of water for agricultural uses was $90 \%$ in 1995 and is expected to reduce to $70 \%$ in 2020 (Pinstrup-Andersen et al., 1997). Constantly increasing population in these countries also increases the pressure on irrigated agriculture to produce more food, especially in view of the 2 to 3 times greater productivity of irrigated agriculture than rainfed agriculture. Hence there is a need to work towards making available water supplies for irrigation more efficient and productive.

This work is concerned with the efficient management of water in irrigation schemes where water flows by gravity through an extensive network of canals to large irrigation areas measuring thousands of hectares. In these schemes water is centrally managed, and the control over the resource is quite easily achievable.

There are many ways to improve the efficiency of use of available water to increase agricultural production in an irrigation scheme. These include improving hardware of the scheme (reservoir desedimentation, raising the dam height, developing the catchment area, lining of canal network, installation of water regulatory and measurement structures, repairing and enhancing maintenance of existing water delivery system, development of onfarm structures, land leveling, automation etc.), adopting water saving irrigation 
methods (pressurized irrigation methods such as sprinkler and drip, improvements in traditional irrigation methods such as skip furrow irrigation method, surge flow irrigation etc ) and improving software of the scheme (adoption of appropriate water distribution methods such as rotational water supply or on demand water supply, developing optimum allocation plans for land and water resources to different crops in the irrigation scheme, institutional reforms, improving capital related activities, improving crop related management practices, etc). These options are generally not alternatives but often applied together. In the late 1970's 'hardware' related options dominated irrigation schemes (Hennessy, 1993), but now this option can provide only marginal increases in water availability. Recently there has been greater interest in 'software' related options that focus on using every drop of available water to its maximum potential. This paper deals with one such 'software' related option i.e. optimum allocation of land and water resources in the irrigation scheme.

The practice of spreading water over a large area has always been a strategy of irrigation in many developing countries, mainly to provide protective irrigation, alleviate famine and raise rural living standards. As a result of this, water is relatively shorter in supply than land and most cultivable command areas do not get enough water (adequate irrigation depth). Water scarcity in these schemes may make deficit irrigation or deliberate stressing to the crops more profitable (English \& Nuss, 1982; Hargreaves \& Samani, 1984; Trimmer 1990; Keller et al., 1992 and Gorantiwar \& Smout, 2003). It is thus important to consider deficit irrigation and to allocate land area and water resources optimally from a water use efficiency point of view to different crops cultivated in different parts of the irrigation scheme (optimum allocation plan) and produce corresponding water delivery schedules. 
Previously several researchers developed methodologies to produce optimum allocation plans (Matanga \& Marino, 1979; Yaron \& Dinar, 1982; Sritharan et al., 1988; Vedula \& Mujumdar 1992; Shyam et al., 1994 and Onta et al., 1995; Mainuddin et al., 1996; Sunantara \& Ramirez, 1997; Wardlaw \& Barnes 1999; Paul et al., 2000 and Sahoo et al., 2001). But these studies were mainly concerned with maximizing the benefits of agricultural production from the irrigation schemes (i.e. productivity) and did not address the issues of distributing the water to farmers in different parts of the command area of irrigation schemes. However as the benefits of irrigation are widely recognized in developing countries, farmers in the command areas of irrigation schemes are concerned about getting an equitable share of water and adequate supply of water (to fill the root zone to field capacity) in addition to maximizing the net benefits. These concerns can be indicated by performance measures of equity, adequacy and productivity, respectively (Gorantiwar and Smout, 2005).

As explained by Abernethy (1986); Bos (1997) and Gorantiwar and Smout (2005), the productivity is related to output from the system (in this case benefits or crop production) in response to the input added to the system (in this case water); equity is the allocation of land area and water among the users in a fair manner (for example proportionate to total land holding or cultivable command area of each farmer) and adequacy deals with matching water supply to the crop grown by each farmer relative to its demand over the irrigated land area. Equitable and adequate water supplies are also necessary to reduce the conflicts at micro levels (i.e. within irrigation scheme). Thus it is important for managers of irrigation schemes to develop allocation plans that optimize productivity, equity and adequacy.

Currently, in the traditional Warabandi systems (North India and Pakistan) and rigid Shejapali systems (Southern India), the irrigation authorities attempt to achieve equity 
by allocating water in proportion to farmers' area or demand (Malhotra, 1982 and Mandavi, 1998). However failure to consider conveyance and field losses, soil type etc., make the allocation inequitable and water delivery schedules unreliable (Latif \& Sarwar, 1994; Khepar et al., 2000 and Smout \& Gorantiwar, 2005). For example, the equitable allocation of water to different outlets at the canal headworks on the basis of the cultivable area of each outlet will result in inequitable distribution of water as the outlets towards the head of the canal will be supplied with a higher proportion compared to outlets towards the tail of the canal because of the losses of water in the process of conveyance. Hence it is necessary to develop an optimum allocation plan and water delivery schedules that include the aforesaid performance measures. This paper presents the methodology to include equity and adequacy while developing the optimum allocation plans.

The inclusion of equity and adequacy requires models that develop the optimum allocation plans considering the heterogeneous nature of the irrigation schemes (i.e. large schemes with varied climate, soils and cropping patterns, different characteristics of water distribution systems, water scarcity etc.). Earlier mentioned studies that aimed at producing optimum allocation plans did not consider all these complexities together. Previous studies produced optimum allocation plans either by considering the entire irrigation scheme as a single field model (Matanga \& Marino, 1979; Yaron \& Dinar, 1982; Mainuddin et al., 1996; Sahoo et al., 2001; Sunantara \& Ramirez, 1997 and Paul et al., 2000) or multi-field models where both land and water resources were not optimised (Sritharan et al., 1988; Shyam et al., 1994 and Onta et al., 1995). Therefore these methodologies can not produce the allocation plans that optimize productivity, equity and adequacy. The simulationoptimization model (Area and Water Allocation Model, AWAM) developed by Gorantiwar (1995) and Smout \& Gorantiwar (2005) for producing the optimum allocation plans and water delivery schedules for irrigation schemes takes account of these complexities. 
Therefore AWAM was chosen to examine the methodology for including equity and adequacy in the allocation process.

The paper briefly explains the model, AWAM, used for including the performance measures followed by the section explaining the methodology developed for inclusion of equity and adequacy while allocating land area and water to different crops cultivated in different parts of the irrigation scheme. The paper further explains the case study used for describing the applicability of the developed methodology followed by discussion on results obtained for the case study.

\section{Description of model- AWAM}

The AWAM model (Gorantiwar, 1995 and Smout \& Gorantiwar, 2005) allocates the land area and available surface water to different crops cultivated in different parts of the irrigation scheme to maximize the net benefits from the irrigation. AWAM model was developed for the irrigation schemes which operate under rotational water supply and not for the schemes where in water is delivered on demand. AWAM model has the following four phases and is executed for each irrigation interval or a set of irrigation intervals over the irrigation season or year.

1. Generation of irrigation strategies

3. Selection of irrigation programmes
2. Preparation of irrigation programmes

4. Optimum allocation of resources

\section{Generation of irrigation strategies}

The area of an irrigation scheme with similar climate (Region), soil (Soil group) and crop is termed as Crop-Soil-Region (CSR) unit (but this is not a physical division of the 
irrigation scheme). As stated earlier, water scarcity in these schemes may make deficit irrigation more profitable. There are several ways to provide deficit irrigation in irrigation scheme for a specified CSR unit. The optimal way has to be selected by considering all CSR units, water availability and characteristics of the command area of the irrigation scheme together (Keller et al., 1992 and Gorantiwar \& Smout, 2003). Hence optimal allocation of water requires estimates of the outputs obtained from several possible strategies that are based on different combinations of deficit (percentage moisture stress in the soil root zone on the day of irrigation) over all the irrigation periods (Gorantiwar \& Smout, 2003). In this phase (Phase 1) irrigation strategies are generated for each CSR unit for a specified set of irrigation intervals. This results in several irrigation strategies for each CSR unit, each with variable deficit for each irrigation.

\section{Preparation of irrigation programme}

In this phase an irrigation programme that consists of information on yield/benefits and irrigation requirement (depth) per irrigation is prepared for each irrigation strategy of each CSR unit for a specified set of irrigation intervals. The irrigation programme is prepared from the following two sub-models.

- SWAB: In response to deficit over each irrigation (specified in irrigation strategy), this sub-model simulates daily soil moisture in the soil root zone, estimates daily actual crop evapotranspiration, the irrigation requirement (depth) per irrigation and the other related parameters.

- CRYB: This sub-model estimates crop yield from the actual evapotranspiration estimated in SWAB sub-model and computes net benefits. 


\section{Selection of irrigation programmes}

Phase 2 may generate many irrigation programmes of which several may not be important. For example the irrigation programmes generated with irrigation strategies having full deficit for successive irrigations may simulate zero yield or the irrigation programmes generated with irrigation strategies having no deficit for successive irrigations may simulate maximum yield but with excessive irrigation water requirement. Moreover some of these programmes may not be optimal and even if included in the optimization model of the fourth phase will not appear in the solution. Incorporation of all these programmes in the optimization model may also make the problem computationally infeasible to solve. Therefore the number of irrigation programmes for the given unit is restricted by selecting only optimal irrigation programmes. Thus the purpose of this phase (Phase-3) is to select for each CSR unit a specified number of irrigation programmes, which are both optimal and efficient according to specified criteria.

\section{Optimum allocation of resources}

This phase (Phase-4) of the model allocates land and water resources optimally to different crops cultivated on different soils in different allocation units. It utilizes the selected irrigation programmes generated in Phase 3.

The entire irrigation scheme is physically divided into a number of smaller units called "Allocation Units" (AU) over which land and water resources are allocated. These units may include different soils and crops however the climate is assumed to be uniform over a particular AU. Note that, the climatic conditions may vary across different AUs. 
The need to divide the irrigation scheme into several AUs arises from the heterogeneous nature and large extent of the irrigation scheme. By dividing the scheme in this way it is possible to make allocation of resources, water delivery schedules and management of the irrigation scheme efficient. The largest possible size of an AU is the size of the irrigation scheme itself and the smallest size of an AU is an individual farm. The intermediate sizes are the command areas of the secondary, tertiary and quaternary canals or groups of these canals.

Phase 4 of the model allocates land and water resources optimally to Crop-Soil (CS) units of each AU. A CS unit is a unit with similar crop and soil properties within an AU. This phase performs the allocation in three stages.

- Stage-1: The phase-3 selects the specified number of irrigation programmes for each CSR unit. In this stage of Phase-4, each CS unit of an AU is assigned with the irrigation programmes of CSR unit having the same crop, soil and climate. As stated earlier CSR unit is not a physical division of the irrigation scheme and hence the distribution and conveyance efficiencies can not be considered while working out the irrigation requirements for each irrigation. The AU is a physical division of the irrigation scheme and hence these efficiencies are included at this stage by determining the irrigation requirements for each irrigation appropriately.

- Stage-2: In this stage, the resources are allocated to each CS unit of each AU for the chosen objective (maximization of net benefits) and constraints (resource availability, physical and output requirement) with the Resource Allocation (RA) sub model. The RA sub model is solved by linear programming. The decision variables are the areas to be irrigated under different crops on each soil type (CS) of each $\mathrm{AU}$ and following different irrigation scheduling as used in irrigation programmes prepared for the corresponding CS of AU (see equation 1). Note that 
these irrigation programmes are prepared in Phase-2; screened in Phase-3 and modified in Stage-1 of Phase-4. The output of the model is thus the area to be irrigated under different crops cultivated on each soil type of AU and the corresponding irrigation programme. Thus this stage gives optimum allocation plan.

- Stage-3: In this stage, the water release schedule for the canal system for the optimum allocation plan is prepared by knowing the irrigation scheduling of the selected irrigation programme for each CS unit of AU (obtained in Stage 2 of Phase $4)$.

\section{Modified model for performance based land area and water allocation plans}

The AWAM Model (Gorantiwar, 1995 and Smout \& Gorantiwar, 2005) described in the previous section maximizes the net benefits and thus in turn maximizes the productivity. In this section the methodology is proposed to include maximization of equity and adequacy in the AWAM model (Figure 1). The objective function proposed in AWAM for the maximization of the net benefits is given below by equation (1). The readers are advised to refer to Gorantiwar (1995) and Smout \& Gorantiwar (2005) for details of the constraints.

$\operatorname{Max} \quad \mathrm{OBJ}=\sum_{\mathrm{a}=1}^{\mathrm{na}} \sum_{\mathrm{s}=1}^{\mathrm{ns}_{\mathrm{a}}} \sum_{\mathrm{c}=1}^{\mathrm{nc}_{\mathrm{sa}}} \sum_{\mathrm{p}=1}^{\mathrm{np}_{\mathrm{csa}}} \mathrm{NB}_{\mathrm{pcsa}} \mathrm{A}_{\mathrm{pcsa}}$

where $\mathrm{a}=$ index for $\mathrm{AU}, \mathrm{s}=$ index for soil group in allocation unit, $\mathrm{c}=$ index for crop in soil group ( $\mathrm{s}^{\text {th }}$ soil group of $\mathrm{a}^{\text {th }}$ allocation $\mathrm{unit}$ ), $\mathrm{p}=$ index for irrigation programme for crop $\left(c^{\text {th }}\right.$ crop in $\mathrm{s}^{\text {th }}$ soil group of $\mathrm{a}^{\text {th }}$ allocation unit), na $=$ total number of allocation units, $\mathrm{ns}_{\mathrm{a}}=$ total number of soil groups in $\mathrm{a}^{\text {th }}$ allocation unit., $\mathrm{nc}_{\mathrm{sa}}=$ total number of crops in $\mathrm{s}^{\text {th }}$ soil 
group of $\mathrm{a}^{\text {th }}$ allocation unit, $\mathrm{nsp}_{\mathrm{csa}}=$ total number of irrigation programmes of $\mathrm{c}^{\text {th }}$ crop in $\mathrm{s}^{\text {th }}$ soil group of $\mathrm{a}^{\text {th }}$ allocation unit, $\mathrm{OBJ}=$ the value of objective function (currency unit), NB $=$ net benefits obtained from $\mathrm{c}^{\text {th }}$ crop irrigated with $\mathrm{p}^{\text {th }}$ irrigation programme on $\mathrm{s}^{\text {th }}$ soil of $\mathrm{a}^{\text {th }}$ allocation unit (currency unit/ha), $\mathrm{A}=$ Area to be allocated to $\mathrm{c}^{\text {th }}$ crop irrigated with $\mathrm{p}^{\text {th }}$ irrigation programme on $\mathrm{s}^{\text {th }}$ soil of $\mathrm{a}^{\text {th }}$ allocation unit (ha).

\section{Inclusion of equity}

This paper attempts to achieve equity in distribution of water over the entire season proportional to the total cultivable land area of AU. This is achieved through adding the constraints (equation 2) in the resource allocation model of Stage-2 of Phase-4 that state that the water to be allocated to a specified AU should be the certain proportion of total water available for allocation excluding the conveyance and distribution losses in irrigation scheme (Gorantiwar 1995). This desired proportion $(\lambda \mathrm{d})$ is based on the total land area of AU compared to the land area of all AUs together. Note that the losses in conveyance and distribution are considered so that the AUs at the tail end of the canal are not disadvantaged.

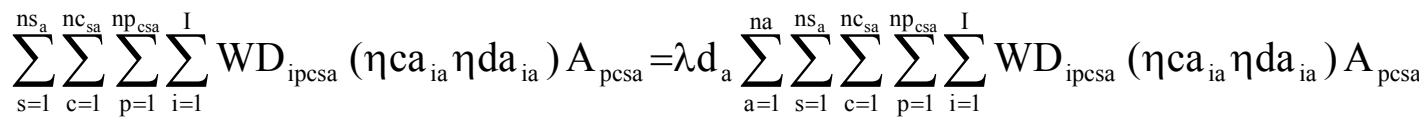

$$
\begin{aligned}
& \text { for } \quad \mathrm{a}=1 \text {, na } \\
& \lambda \mathrm{d}_{\mathrm{a}}=\frac{\mathrm{TA}_{\mathrm{a}}}{\sum_{\mathrm{a}=1}^{\mathrm{na}} \mathrm{TA}_{\mathrm{a}}}
\end{aligned}
$$

where, 
$\mathrm{i}=$ index for irrigation, $\mathrm{I}=$ total number of irrigations, $\mathrm{WD}_{\text {ipcsa }}=$ the depth of water to be delivered from the headworks to $\mathrm{c}^{\text {th }}$ crop irrigated with $\mathrm{p}^{\text {th }}$ irrigation programme on $\mathrm{s}^{\text {th }}$ soil of $\mathrm{a}^{\text {th }}$ allocation unit for $\mathrm{i}^{\text {th }}$ irrigation $(\mathrm{m}), \eta \mathrm{ca}_{\mathrm{ia}}=$ conveyance efficiency of canal network for $\mathrm{i}^{\text {th }}$ irrigation for $\mathrm{a}^{\text {th }}$ allocation unit (fraction), $\eta \mathrm{da}_{\mathrm{ia}}=$ distribution efficiency for $\mathrm{i}^{\text {th }}$ irrigation of $\mathrm{a}^{\text {th }}$ allocation unit (fraction), $\mathrm{TA}_{\mathrm{a}}$ is the total cultivable area or land holding of $\mathrm{a}^{\text {th }}$ allocation unit (ha).

\section{Inclusion of adequacy}

As stated earlier, adequacy deals with matching water supply to the crop grown by each farmer relative to its demand. The AWAM model while allocating land area and water resources makes use of several irrigation programmes corresponding to irrigation strategies that are based on deficit irrigation and finally selects one for each CS unit of AU. The irrigation scheduling corresponding to a selected irrigation programme may not match the crop water demand and hence the water deliveries (obtained from Stage-3 of Phase-4) may not be adequate. Therefore when adequacy is to be maximized, it is proposed to obtain in Phase-2, only one irrigation programme for each CS unit that schedules the water deliveries matching the crop water demand (i.e. to deliver the depth of water to CS unit of AU such that at every irrigation the soil moisture in the root zone of the crop is raised to field capacity) and consider this irrigation programme for optimization in Phase 3. The allocation plan obtained from RA sub model, in this case, will schedule the water deliveries according to crop water demand on the allocated land area to the different crops in AU. This allocation plan may give lower total net benefits from the irrigation scheme compared to the allocation plan that considers several irrigation strategies based on deficit irrigation. This is because deficit irrigation would allow available water in an irrigation 
scheme to spread over a larger area and hence, though the net benefits per unit area are decreased, the total net benefits from the irrigation scheme may be greater when compared to full irrigation. It is to be noted here that the water deliveries are adequate over the area which is allocated for irrigation and this area is obtained from RA sub model.

\section{Different scenarios resulting from combination of productivity, equity and adequacy and their quantification}

As stated earlier, the AWAM model presented with modifications in this paper optimizes the productivity performance measure, while maximizing the other two performance measures of equity and adequacy. This results in the following four scenarios (Figure 1).

1. Optimization of productivity

2. Optimization of productivity for maximum equity of supply to irrigated areas

3. Optimization of productivity for maximum adequacy of supply to irrigated areas

4. Optimization of productivity for maximization of equity and adequacy

Productivity is quantified as the ratio of the output (measured as net benefits in monetary units) to the maximum output attainable from the resources available (land and water). Equity is related to the distribution of water to different allocation units based on cultivable command area (CCA) and can be quantified by allocation ratios of different AUs as proposed by Gorantiwar (1995) and Gorantiwar \& Smout (2005). The allocation ratio for a specified $\mathrm{AU}$ is the ratio of actual allocation proportion as a result of allocation of water to desired allocation proportion for this $\mathrm{AU}(\lambda \mathrm{d})$. The interquartile allocation ratio (IQAR) is used as the measure of equity. IQAR is defined as "the average allocation ratio 
of the poorest quarter divided by the average allocation ratio of the best quarter" (Gorantiwar, 1995 and Gorantiwar \& Smout 2005). Adequacy is the ratio of water allocated and the maximum water demand for a particular set of irrigation intervals.

The maximum productivity is obtained by generating several irrigation strategies that allocate water optimally. Thus the performance measure of productivity is addressed in Phase-1 and Stage-2 of Phase-4 of the model. In the modified AWAM model maximization of equity is addressed in Stage- 2 of Phase- 4 of the model by allocating water to each AU proportional to CCA of the AU. The maximum adequacy is obtained by irrigating the CSR unit to its field capacity (full irrigation) and thus this issue is addressed in Phase-2. It should be noted here that in addition to the constraints for equity, other constraints are also included to account for total water use, physical capacity, resource availability and output requirements. The details can be found in Gorantiwar (1995) and Smout \& Gorantiwar (2005).

\section{Case study irrigation scheme}

In this paper, the applicability of modified AWAM model to obtain the performance based land area and water allocation plans is demonstrated with the help of case study on the "Nazare Medium Irrigation Scheme" in a semi-arid region of Maharashtra State of India. This irrigation scheme is representative of storage reservoir irrigation schemes that operate under rotational water supply in south Asia.

There are three distinct crop seasons within the irrigation scheme: winter (Rabi), 15th October to 14th February; summer, 15th February to 14 June; and rainy (Kharif), 15th June to 14th October. As little rainfall is received in the Rabi season, the crops grown is this season are supplied with irrigation water. In the summer, there is no rainfall and 
evapotranspiration is high, therefore irrigations are applied to a limited extension. Most of the rainfall is received in the Kharif (monsoon) season. Therefore crops grown in this season need one or two irrigations (protective irrigations) only. The irrigations during Kharif season are of little interest in this study as the reservoir fills during this season. Therefore in this study, the irrigation season was considered to spread over Rabi and summer crop seasons only. Normally the irrigation interval in Rabi season is 21 days and in summer season is 14 days.

The gross capacity and dead storage capacity of the reservoir are 22.31 and 5.68 $\mathrm{Mm}^{3}$, respectively. One main canal originates from the headworks. The full supply discharge and the length of the main canal are $1.53 \mathrm{~m}^{3} / \mathrm{s}$ and $3.05 \mathrm{~km}$, respectively. One distributory canal with carrying capacity of $1.53 \mathrm{~m}^{3} / \mathrm{s}$ emerges from the main canal, the length of which is $11.75 \mathrm{Km}$. Some of the outlets are provided with screw type gates and some are without gates. However, the screw type gates are being considered for all the outlets. The cultural command area (CCA) of the irrigation scheme is 3539 ha. There are 28 direct outlets ( 4 on the main canal and 24 on the distributory canal) and four minors (all on distributory canal) with 9 outlets. The details of the outlets on the minors could not be obtained and therefore CCA of all 28 outlets and 4 minors were considered as allocation units, resulting in 32 AUs. The data related to allocation units interms of different efficiencies (application, distribution and conveyance); soil types etc were obtained from different sources (Stofkoper \& Tilak, 1992 and Irrigation Research Development, 1992)

The climatological data were collected from the daily records of the Meteorological Observatory of the nearest agricultural university (Mahatma Phule Agricultural University, Rahuri). The same data series was used for the reservoir (for estimating the water evaporation) and command area (for estimating the reference crop evapotranspiration and bare soil evaporation). The climate over the entire command area was assumed as uniform 
and thus there was only one 'Region'. The command area is characterized with four different types of soils. In the present study as two crop seasons formed the irrigation season, gram, sorghum, onion, wheat (Rabi crops), groundnut and sunflower (summer crops) were considered in the analysis. Based on the previous trend in the irrigation scheme, a fixed cropping distribution was assumed of gram- $25 \%$, sorghum- $20 \%$, onion$10 \%$ and wheat $-15 \%$ in Rabi and Sunflower $-10 \%$ and groundnut-20\% in summer season. This fixed cropping distribution was considered for investigating the issues under consideration in this paper, though the AWAM model can also consider the free cropping distribution in which the model is free to select any crops depending on which crops produce maximum total net benefits from the irrigation scheme (refer to Gorantiwar, 1995 and Smout and Gorantiwar, 2005).

\section{Results}

The allocation plans and water delivery schedules were obtained for the four scenarios stated earlier. For each scenario, seven sets of irrigation interval were considered. These were: 14 days (I-14); 21 days (I-21); 28 Days (I-28); 35 days (I-35) \{both Rabi and summer seasons \}; 21 in Rabi and 14 in summer (I-21-14); 28 in Rabi and 21 in summer (I28-21); and 35 in Rabi and 21 in summer (I-35-21). The productivity, equity and adequacy values associated with the allocation plans and water delivery schedules, for the four scenarios and seven sets of irrigation interval are presented in Figure 2.

The maximum net benefit $B_{\max }$, was obtained for the irrigation interval of 14 days under the "optimizing productivity" scenario. Hence the productivity values for different scenarios and irrigation intervals were computed with reference to $\mathrm{B}_{\max }$ by considering this value as the maximum attainable. 
Figure 2 (a) shows that the irrigation interval influences the productivity. However, the trend of influence depends on the scenarios. It is observed from Figure 2 (a) that the productivity values decrease with the irrigation interval for both "optimizing productivity" and "optimizing productivity for maximum equity" scenarios. This is due to the consideration of several irrigation strategies based on the deficit irrigation in the model for optimum productivity. According to this approach, deficit irrigation is followed by an optimum combination of skipping the irrigation and applying lower irrigation depths (less than the full irrigation depths). The smaller irrigation interval adds to the flexibility in skipping the irrigations for a particular crop-soil-region unit and hence optimizes the use of water more efficiently than the larger irrigation interval.

In the scenarios of "optimizing productivity for maximum adequacy" and "optimizing productivity for maximum adequacy and equity", the productivity values marginally increase with irrigation interval until an irrigation interval of 21 days after which it drops drastically. These scenarios use a single irrigation strategy of full irrigation i.e. providing the irrigation to raise the soil moisture in the root zone to field capacity. According to this strategy, the irrigation interval of 14 days gives maximum net returns per unit area for most of the crops considered in this study (Gorantiwar, 1995). Prolonging the interval to 21 days causes the deficit irrigation i.e. irrigating a larger area and giving slightly higher total net returns. However when the irrigation interval is further prolonged from 21 days to 35 days, the crops were subjected to excessive stress with drastic yield reduction and thus reducing the productivity greatly. In Figure 2 (a), on comparing productivity values between the "optimizing productivity" and "optimizing productivity for maximum equity" scenarios and the "optimizing productivity for maximum adequacy" and "optimizing productivity for maximum adequacy and equity" scenarios, it is seen that the productivity values are lower 
for the scenarios for maximum equity. This is due to the fact that for maximum equity less productive allocation units are also allocated with water and thus reducing the productivity.

As expected the equity is 1.0 for the scenarios of maximum equity. However it should be noted that for the scenarios that do not include maximum equity, the resulting equity is zero (Figure 2 (b)). Note that since equity is zero, none of the two columns for the options "maximization of productivity" and "optimization of productivity for maximum adequacy" appear in the Figure 2 (b). This indicates that the resources are getting allocated to only highly productive allocation units (with no concern for equity).

Similarly adequacy is 1.0 for the scenarios of maximum adequacy. For the scenarios that do not include maximum adequacy, adequacy ranges from 0.6 to 0.8 (Figure 2 (c)), and there is a trend of slight increase in adequacy with the increase in irrigation interval. This indicates that for scenarios that do not include maximum adequacy, when irrigation intervals are increased, the depth of irrigation tends towards the full irrigation depth but over the lesser land area (for obtaining maximum productivity) compared to when irrigation intervals are smaller. This in turn reduces productivity and increases adequacy for larger irrigation intervals.

Table 1 summarizes the performance measures of the optimal solution (amongst different sets of irrigation interval) obtained for each scenario. It can be seen from Table 1 that the reduction in productivity between scenarios 'optimization of productivity' and 'optimization of productivity for maximum equity'; 'optimization of productivity' and 'optimization of productivity for maximum adequacy'; and 'optimization of productivity' and 'optimization of productivity for maximum equity and adequacy' is 12,22 , and 32 per cent respectively. This indicates the loss in productivity for ensuring maximum adequacy, maximum equity and both respectively. It can also be observed from the first and second rows of Table 1 that when ensuring maximum equity, there is a reduction in productivity. 
This can be explained by the fact that for maximum equity, resources are allocated equally to all the allocation units irrespective of their productivity.

Similarly the first and third rows of Table 1 indicate that when ensuring maximum adequacy, there is a reduction in productivity. This is because in the process of ensuring maximum adequacy, less area is allocated for irrigation. Thus lower total net benefits are obtained from the irrigation scheme (hence reduction in productivity) though the adequate irrigation gives higher net benefits per unit area compared to when maximum productivity is achieved (by adopting deficit irrigation).

The Table 1 also indicates that when adequacy is maximum i.e. 1.0, then equity is 1.0 and 0.0 and when adequacy is minimum (i.e. $0.66-0.68$ ), then also equity is 1.0 and 0.0 . This is because of the fact that the adequacy is computed over the land area which is allocated for irrigation and the model attempts to achieve equity (or inequity) for maximum adequacy or maximum productivity (minimum adequacy). Thus clearly the three performance measures of productivity, equity and adequacy are in conflict with each other.

For this case study of Nazare Irrigation Scheme, where the objective is to achieve maximum equity with the productivity, the allocation plan for the scenario of maximum equity would be useful (shown in shaded portion of Table 1). The details of this allocation plan are presented in Table 2 (see the Area and Water columns of 'Allocation by proposed methodology'). The Table 2 also presents the allocation by current practice (see the Area and Water columns of 'Allocation by current practice'). As stated earlier the current practice allocates the resources without considering the irrigation losses. These losses are different for different AUs. If we compare the allocation ratios of current practice and proposed methodology (presented in Table 2), it is clearly seen that the current practice allocates more than desired water to the AUs near the head of the canal and less to the AUs 
at the tail of the canal (allocation ratios vary from 1.47 to 0.73 ), whereas the proposed methodology allocates water resources equitably (allocation ratio is 1.0 for all AUs). This is also reflected in the value of equity which is 1.00 for the proposed methodology and 0.58 for the current practice (however current practice increased the productivity slightly i.e. by $2.5 \%$ ). This type of inequitable distribution by current practice will not give confidence to the farmers and hence farmers will tend to draw as much water as possible whenever they get water and thus the entire schedule becomes unreliable. Hence the need to consider the schedule obtained by proposed methodology which is equitable.

Figure 3 shows the relationship between productivity and equity for the irrigation interval of 14 days (adequacy is not considered in the development of this relationship). It is observed that with the increase in equity, the productivity decreases. Note that the productivity is high when equity is low as water is not allocated to less productive units such as units at tail end and units with less productive soils. However for high equity, water spreads proportionally over all the units, thus making water allocation to less productive units. This is in contrast to Abernethy (1986) and Khepar et al. (2000) who argued that the equitable distribution of water is also necessary for maximizing productivity. Their argument was based on the notion that the farmers at head apply more water than is needed for potential yield and excess water will not improve the productivity but will reduce it. Had that excess water been diverted to other parts of the scheme requiring water the production would have increased. However when water is scarce and managed optimally, the productivity and equity are conflicting issues, as found in this study.

\section{Conclusions}


Irrigation schemes in the semi arid and arid regions in developing countries are characterized by water scarcity, the heterogeneity in soils, crops, climate, and water distribution network and the large number of users. Therefore the development of optimum land and water allocation plans and operable water delivery schedules that consider these aspects are valuable for these irrigation schemes. Earlier studies aimed at producing the optimum allocation plans but did not consider the complexities associated with water scarcity; the heterogeneity in soils, crops, climate; water distribution network etc. The simulation-optimization model (Area and Water Allocation Model, AWAM) produces the optimum allocation plans and water delivery schedules for the irrigation schemes with limited water and under rotational water supply. This model considers all associated complexities.

According to the local situation, the performance objectives of productivity, equity or adequacy may be appropriate. Thus it is important that irrigation managers have access to allocation plans and schedules that optimize these performance measures. The previous studies did not incorporate these performance measures together. This study developed the methodology to include these performance measures while developing the optimum allocation plans, and incorporated this methodology into the AWAM model. The inclusion of these performance measures enables the irrigation authorities to select the appropriate allocation plans depending on the local situation and to match the performance of the irrigation scheme to the objectives/goals of the irrigation scheme.

The allocation plans and the water delivery schedules were obtained for the case study of Nazare Irrigation Scheme, Maharashtra, India for different sets of irrigation intervals and for four different scenarios: optimization of productivity; optimization of productivity for maximum equity of supply to irrigated areas; optimization of productivity for 
maximum adequacy of supply to irrigated areas; and optimization of productivity for maximization of equity and adequacy. The results indicated that:

- Productivity values decrease with the irrigation interval for both "optimizing productivity" and "optimizing productivity for maximum equity" scenarios.

- In the case of "optimizing productivity for maximum adequacy" and "optimizing productivity for maximum adequacy and equity" scenarios the productivity values marginally increase with irrigation interval until an irrigation interval of 21 days. Beyond this productivity drops drastically.

- Productivity values are lower for the scenarios for maximum equity, as water is also allocated to less productive allocation units.

- For scenarios with maximum equity, equity is 1.0 . For scenarios that do not include maximum equity the resulting equity is zero. This shows resources are being allocated to only highly productive allocation units (no concern for equity).

- Adequacy is 1.0 for scenarios of maximum adequacy. For the other scenarios that do not include adequacy, adequacy ranges from 0.6 to 0.8 .

In general, the results indicated that the performance objectives of productivity, equity and adequacy conflict with each other, if the water resources are allocated optimally. For the irrigation schemes where water resources are limited such as Nazare Irrigation Scheme, India, where the objective is to achieve maximum equity with the productivity, the allocation plan for the scenario of maximum equity that can be obtained with the modified AWAM model would be useful. It should be noted here that this paper only considers methodology for optimum water allocation for canal irrigation schemes under rotational water supply from water sources such as a storage reservoir. In some circumstances however optimum water allocation plan may entail combining the use of canal water with 
pond water and groundwater (wells). However the issue of conjunctive use of water for irrigation is not investigated in this paper. 


\section{References}

Abernethy, C.L. 1986. Performance Measurement in Canal Water management: A Discussion. ODI-IIMI Irrigation Management Network Paper 86/2d, pp. 25.

Bos, M.G. 1997. Performance indicators for irrigation and drainage. Irrigation and Drainage Systems 11: 119-137.

English, M. \& Nuss, G. S. 1982. Designing for Deficit Irrigation. Journal of Irrigation and Drainage Engineering, ASCE 108(IR2):91-106.

Gorantiwar, S. D. 1995. A Model for Planning and Operation of Heterogeneous Irrigation Schemes in Semi-Arid Regions under Rotational Water Supply A Ph. D. Thesis, Loughborough University of Technology, Loughborough, Leicestershire, UK.

Gorantiwar, S.D. \& Smout, I. K. 2005. Performance assessment of irrigation water management of heterogeneous irrigation schemes: 1. A framework for evaluation. Irrigation and Drainage Systems 19:1-36.

Gorantiwar, S.D. \& Smout, I.K. 2003. Allocation of scarce water resources using deficit irrigation in rotational systems. Journal of Irrigation and Drainage Engineering, ASCE 29(3):155-163.

Hargreaves, G. H. \& Samani, Z. A. 1984. Economic Considerations of Deficit Irrigation. Journal of Irrigation and Drainage Engineering, ASCE 110(4):343-358.

Hennessy, J. 1993. Water Management in the 21st Century. In: Proceedings of the $15^{\text {th }}$ Congress on Irrigation and Drainage: Water Management in the Next Century held at the Hague, the Netherlands, 1-J, pp. 1-31. 
Irrigation Research Development. 1992. Report of Pre-Irrigation Soil Survey of the Command of Nazare Medium Irrigation Project, Dist.: Pune. Irrigation Research Development, Department of Irrigation, Pune, Maharashtra State, India.

Keller, J., Sivanappan, R. K. \& Varadan, K. M. 1992. Design Logic for Deficit Drip Irrigation of Coconut Trees. Irrigation and Drainage Systems 6:1-7.

Khepar, S.D., Gulati, H.S., Yadav, A.K. \& Brar, T.P.S. 2000. A Model for Equitable Distribution for Canal Water. Irrigation Science 19:191-197.

Latif, M. \& Sarwar, S. 1994. Proposal for Equitable Water Allocation for Rotational Irrigation in Pakistan. Irrigation and Drainage Systems 8:35-48.

Mainuddin, M., Gupta A.D., \& Onta, P.R. 1996. Optimal Crop Planning Model for an Existing Groundwater Irrigation Project in Thailand. Agricultural Water Management 33:43-62.

Malhotra, S.P. 1982. The Warabandi System and its Infrastructure. Central Board of Irrigation and Power, New Delhi, India.

Mandavi, A.B. 1998. Modernization of Irrigation System Operational Management by Way of Canal Automation in India. In: Modernization of Irrigation System Operations: Proceedings of the 5th ITIS Network International Meeting, Aurangabad, India, 28-30 October 1998, the Food and Agriculture Organization of the United Nations, Regional Office for Asia and the Pacific, Maliwan Mansion, 39 Phra Athit Road Bangkok 10200, Thailand.

Matanga, G. B. \& Marino, M. A. 1979. Irrigation Planning 1. Cropping Pattern. Water Resources Research 15(3):672-678.

Onta, P. R., Loof, R. \& Banskota, M. 1995. Performance Based Irrigation Planning under Water Shortage. Irrigation and Drainage Systems 9:143-162. 
Paul, S., Panda, S.N. \& Nagesh Kumar, D. 2000. Optimal irrigation allocation: A multilevel approach. Journal of Irrigation and Drainage Engineering, ASCE 126(3): 149-156.

Pinstrup-Andersen, P., Pandya-Lorch, R. \& Rosegrant, M.W. 1997. The world food situation: recent developments, emerging issues, and long- term prospects. Food Policy Report, International Food Policy Research Institute, Washington, D.C., December 1997, 36pp.

Sahoo, G.B., Loof, R., Abernethy, C.L. \& Kazama, S. 2001. Reservoir Release Policy for Large Irrigation System. Journal of Irrigation and Drainage Engineering, ASCE 127(5):302-310.

Shyam, R., Chauhan, H. S. \& Sharma, J. S. 1994. Optimal Operation Scheduling Model for a Canal System. Agricultural Water Management 26:213-225.

Smout, I.K. \& Gorantiwar, S.D. 2005. A Multilevel Approach for Optimizing Land and Water Resources and Irrigation Deliveries for Tertiary Units in Large Irrigation Schemes: 1.Method. Journal of Irrigation and Drainage Engineering, ASCE 131(3): 254-263.

Sritharan, S. I., Clyma, W. \& Richardson, E. V. 1988. On-farm Application System Design and Project-Scale Water Management. Journal of Irrigation and Drainage Engineering, ASCE 114(4):622-643.

Stofkoper, J. \& Tilak, M.B.G. 1992. A Report on Action Research Program in Nazare Medium Irrigation Project, Maharashtra State. Pune Irrigation Division, Pune, India.

Sunantara, J.D. \& Ramirez, J.A. 1997. Optimal Stochastic Multicrop Seasonal and Intraseasonal Irrigation Control. Journal of Water Resources Planning and Management, ASCE 123(1):39-48. 
Trimmer, W. L., 1990. Applying Partial Irrigation in Pakistan. Journal of Irrigation and Drainage Engineering, ASCE 116(3):342-353.

Vedula S., \& Mujumdar, P.P. 1992. Optimal Reservoir Operation for Irrigation of Multiple Crops. Water Resource Research 28(1):1-9.

Wardlaw, R. \& Barnes, J. 1999. Optimal Allocation of Irrigation Water Supplies in Real Time. Journal of Irrigation and Drainage Engineering, ASCE 125(6):345-354.

Yaron, D. \& Dinar, A. 1982. Optimum Allocation of Farm Irrigation Water during Peak Seasons. American Journal of Agricultural Economics 64 (November):681-689. 
Table 1. The maximum values of performance measures for different scenarios

\begin{tabular}{lcccc}
\hline \multirow{2}{*}{ Scenarios } & \multicolumn{3}{c}{ Performance Measures } & \multirow{2}{*}{$\begin{array}{c}\text { Irrigation } \\
\text { interval }\end{array}$} \\
\cline { 2 - 4 } & Productivity & Equity & Adequacy & \\
\hline Optimization of productivity & 1.0 & 0.0 & 0.675 & $\mathrm{I}-14$ \\
$\begin{array}{l}\text { Optimization of productivity } \\
\text { for maximum equity }\end{array}$ & 0.88 & 1.0 & 0.66 & $\mathrm{I}-14$ \\
$\begin{array}{l}\text { Optimization of productivity for } \\
\text { maximum adequacy }\end{array}$ & 0.78 & 0.0 & 1.0 & $\mathrm{I}-21$ \\
$\begin{array}{l}\text { Optimization of productivity for } \\
\text { maximum equity and adequacy }\end{array}$ & 0.68 & 1.0 & 1.0 & $\mathrm{I}-21$ \\
\hline
\end{tabular}


Table 2. Land area and water allocation plans by current practice and proposed methodology

\begin{tabular}{|c|c|c|c|c|c|c|c|}
\hline \multirow[t]{2}{*}{ AU } & \multirow{2}{*}{$\begin{array}{l}\text { CCA } \\
\text { of AU } \\
\text { (ha) }\end{array}$} & \multicolumn{3}{|c|}{ Allocation by current practice } & \multicolumn{3}{|c|}{ Allocation by proposed methodology } \\
\hline & & $\begin{array}{c}\text { Area } \\
\text { (ha) }\end{array}$ & $\begin{array}{l}\text { Water } \\
\text { (ha-m) }\end{array}$ & $\begin{array}{c}\text { Allocation } \\
\text { ratio }\end{array}$ & Area (ha) & $\begin{array}{l}\text { Water } \\
\text { (ha-m) }\end{array}$ & $\begin{array}{c}\text { Allocation } \\
\text { ratio }\end{array}$ \\
\hline 1 & 39 & 27.29 & 11.82 & 1.47 & 18.55 & 8.04 & 1.00 \\
\hline 2 & 36 & 22.83 & 10.83 & 1.46 & 15.59 & 7.42 & 1.00 \\
\hline 3 & 8 & 5.02 & 2.38 & 1.44 & 3.47 & 1.65 & 1.00 \\
\hline 4 & 27 & 16.15 & 7.66 & 1.38 & 11.73 & 5.56 & 1.00 \\
\hline 5 & 395 & 194.44 & 108.10 & 1.33 & 146.38 & 81.38 & 1.00 \\
\hline 6 & 33 & 18.89 & 8.99 & 1.32 & 14.29 & 6.80 & 1.00 \\
\hline 7 & 59 & 31.77 & 15.07 & 1.24 & 25.62 & 12.16 & 1.00 \\
\hline 8 & 22 & 11.54 & 5.48 & 1.21 & 9.55 & 4.53 & 1.00 \\
\hline 9 & 211 & 86.58 & 51.44 & 1.18 & 73.31 & 43.47 & 1.00 \\
\hline 10 & 68 & 34.75 & 16.49 & 1.18 & 29.53 & 14.01 & 1.00 \\
\hline 11 & 62 & 30.83 & 14.63 & 1.14 & 26.93 & 12.77 & 1.00 \\
\hline 12 & 142 & 55.34 & 32.88 & 1.12 & 49.24 & 29.26 & 1.00 \\
\hline 13 & 127 & 61.96 & 29.40 & 1.12 & 55.15 & 26.17 & 1.00 \\
\hline 14 & 81 & 38.39 & 18.21 & 1.09 & 35.18 & 16.69 & 1.00 \\
\hline 15 & 217 & 102.85 & 48.79 & 1.09 & 94.24 & 44.71 & 1.00 \\
\hline 16 & 82 & 38.89 & 17.30 & 1.02 & 37.99 & 16.89 & 1.00 \\
\hline 17 & 145 & 62.92 & 30.63 & 1.03 & 61.36 & 29.87 & 1.00 \\
\hline 18 & 147 & 60.96 & 29.68 & 0.98 & 62.20 & 30.29 & 1.00 \\
\hline 19 & 118 & 50.15 & 23.79 & 0.98 & 51.25 & 24.31 & 1.00 \\
\hline 20 & 661 & 205.91 & 125.33 & 0.92 & 223.76 & 136.19 & 1.00 \\
\hline 21 & 65 & 25.47 & 12.12 & 0.91 & 28.14 & 13.39 & 1.00 \\
\hline 22 & 156 & 61.13 & 29.09 & 0.91 & 67.54 & 32.14 & 1.00 \\
\hline 23 & 30 & 10.68 & 5.20 & 0.84 & 12.69 & 6.18 & 1.00 \\
\hline 24 & 37 & 13.17 & 6.41 & 0.84 & 15.66 & 7.62 & 1.00 \\
\hline 25 & 89 & 31.33 & 15.26 & 0.83 & 37.66 & 18.34 & 1.00 \\
\hline 26 & 93 & 32.74 & 15.94 & 0.83 & 39.35 & 19.16 & 1.00 \\
\hline 27 & 115 & 38.62 & 18.81 & 0.79 & 48.66 & 23.69 & 1.00 \\
\hline 28 & 30 & 9.98 & 4.86 & 0.79 & 12.69 & 6.18 & 1.00 \\
\hline 29 & 32 & 10.64 & 5.18 & 0.79 & 13.54 & 6.59 & 1.00 \\
\hline 30 & 87 & 27.37 & 13.33 & 0.74 & 36.81 & 17.92 & 1.00 \\
\hline 31 & 35 & 10.76 & 5.24 & 0.73 & 14.81 & 7.21 & 1.00 \\
\hline 32 & 90 & 27.67 & 13.47 & 0.73 & 38.08 & 18.54 & 1.00 \\
\hline Total & 3539 & 1457.02 & 753.81 & $0.58^{*}$ & 1410.95 & 729.15 & $1.00^{*}$ \\
\hline
\end{tabular}




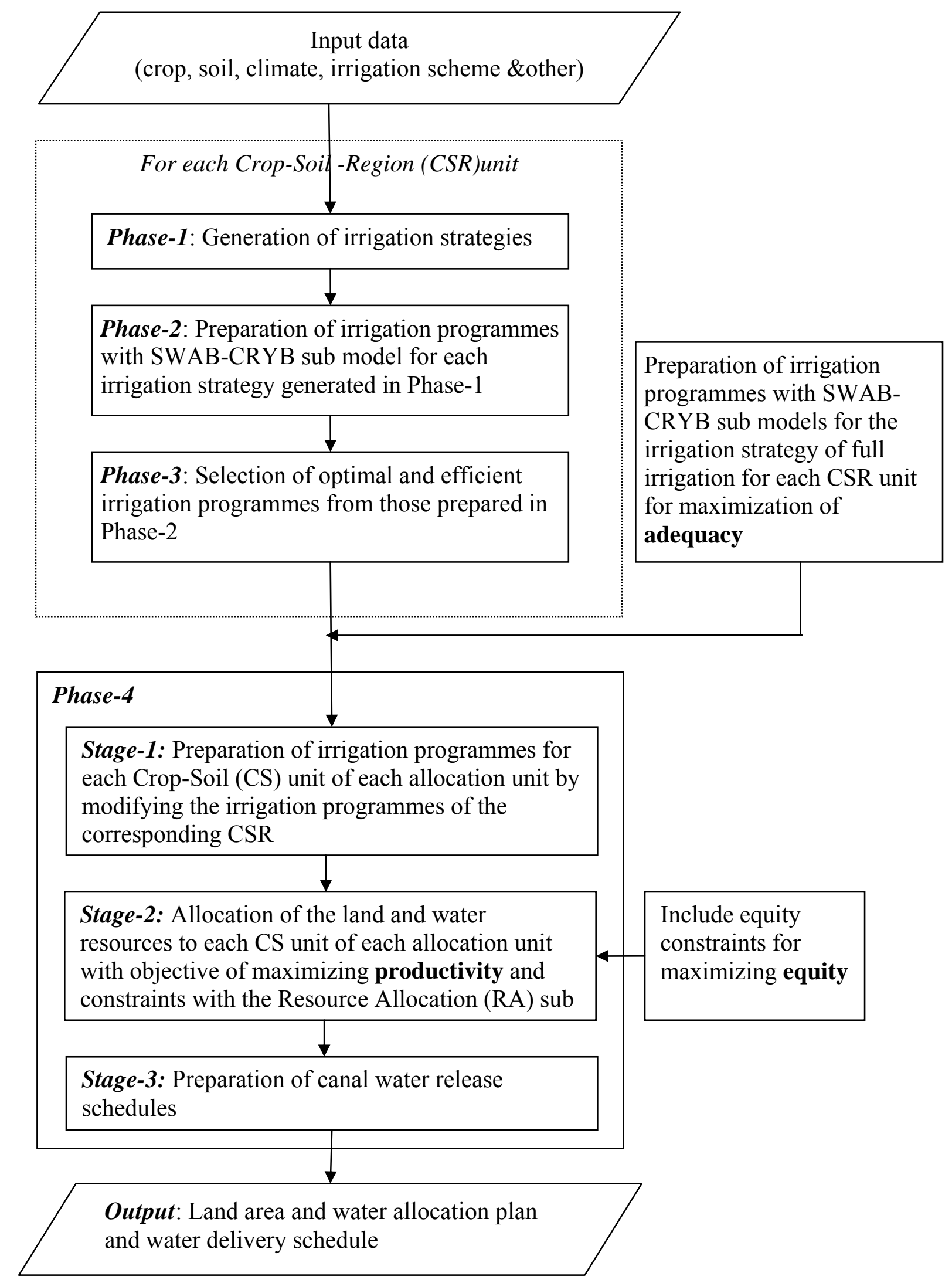

Figure 1. The flowchart of the modified Area and Water Allocation Model (AWAM) 


\section{(a) Productivity}

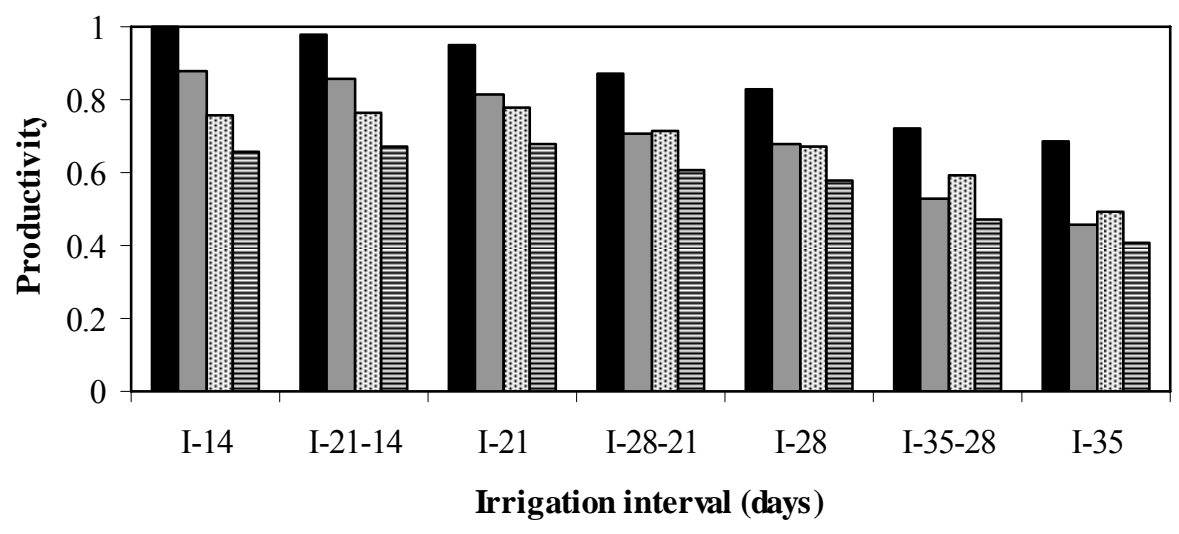

(b) Equity

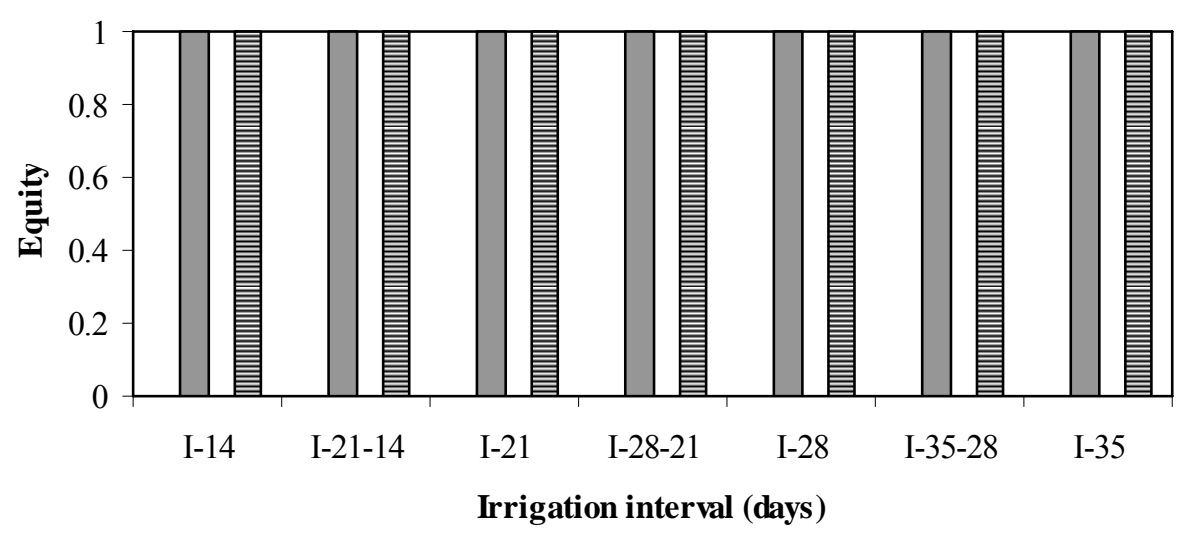

(c) Adequacy

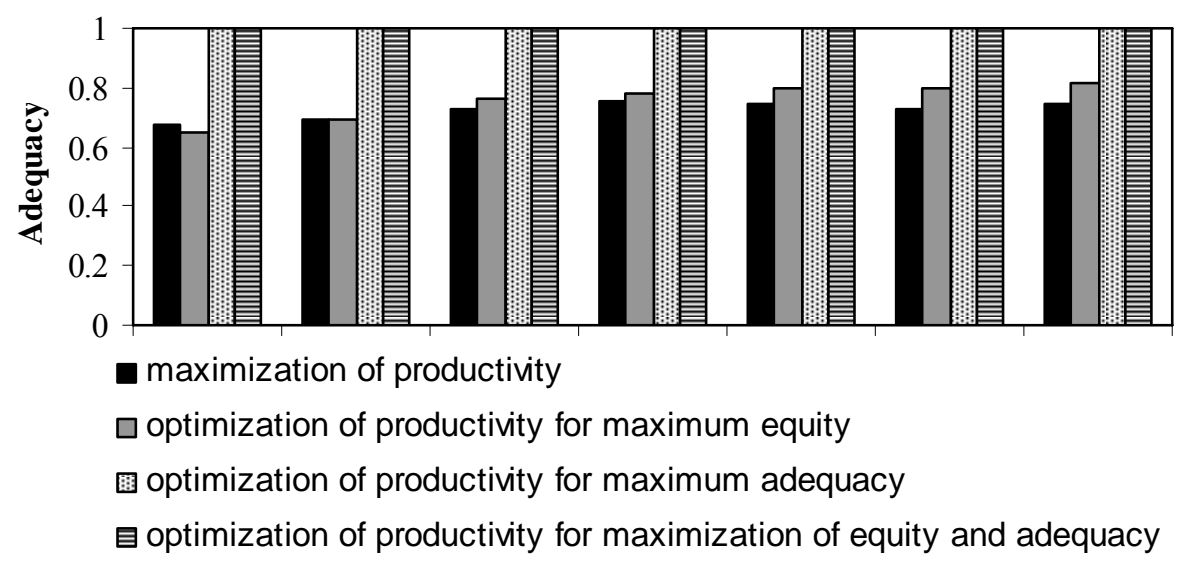

Figure 2. Productivity, equity and adequacy as influenced by different scenarios for different irrigation intervals for Nazare Medium Irrigation Scheme, India. 


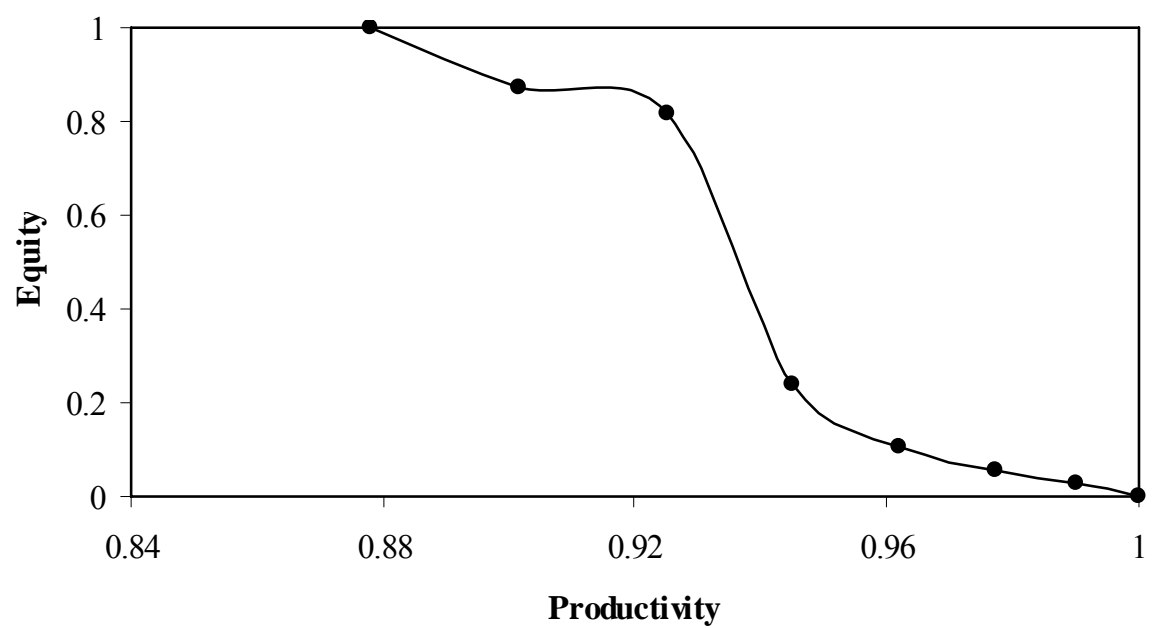

Figure 3. The relationship between productivity and equity for irrigation interval of 14 days for Nazare Medium Irrigation Scheme, India 